\title{
Biological Inspirations in Details Construction and Manufacturing Processes
}

\author{
Adam Ruszaj 1, 2, *, Mariusz Cygnar², Grzegorz Budzik³ \\ ${ }^{1}$ Institute of Production Engineering, Cracow University of Technology, Cracow, Poland \\ ${ }^{2}$ Institute of Technology, State University of Applied Sciences, Nowy Sącz, Poland \\ ${ }^{3}$ Department Machine Construction, Rzeszów University of Technology, Rzeszów, Poland
}

\section{Email address:}

ruszaj@mech.pk.edu.pl (A. Ruszaj)

${ }^{*}$ Corresponding author

\section{To cite this article:}

Adam Ruszaj, Mariusz Cygnar, Grzegorz Budzik. Biological Inspirations in Details Construction and Manufacturing Processes. American Journal of Mechanics and Applications. Vol. 7, No. 3, 2019, pp. 49-55. doi: 10.11648/j.ajma.20190703.13

Received: July 24, 2019; Accepted: September 25, 2019; Published: October 23, 2019

\begin{abstract}
Any machine-tool or manufacturing process designed by engineers is not as excellent as plants, animals or processes occurring in natural surroundings, which have been designed by The NATURE in evolution process. The bridge between solutions occurring in natural surroundings and technique create the BIONIC. The bionic (from Greece words "bios life" and "mimesis - to mimic") is an interdisciplinary science which investigated alive organisms, materials and processes occurring in the natural surroundings in order to apply results in technical solutions. The bionic achievements have been applied in many branches of technique. Nowadays it is very important to start the intensive research on bio-inspired applications in the area of production engineering. However it is not optimistic that there are many factories and engineers who don't apply bio-inspirations in their professional activities. The results of investigations presented in this paper can encourage for wider applications of bioinspirations in engineering. So, in the paper there are presented general informations about methodology of bio-inspired design. Then, the practical application and results are presented. The special attention is payed for bio-improvements in manufacturing systems, mechanical parts shape and inside structure designing, special properties of surface layer creation and innovations in drilling and grinding operations. The general idea of the paper is to generate some kind of braking down in the classical view on engineering and manufacturing processes further development.
\end{abstract}

Keywords: Biological Inspirations, Mechanical Parts, Construction, Manufacturing

\section{Introduction}

Bionic (from Greece bios-life and mimesis - mimic) is an interdisciplinary branch of science which investigate the alive organisms (plants and animals), materials and processes occurring in natural surroundings in order to apply results in technique [1-4]. The Man from its beginning observed phenomena, processes and alive organisms in order to solve basic problems of his life. Now, thanks to the science and technique development the above mentioned observations are more precise and can be widely applied in architecture, machine building, automation, electronic, automatic, robotic, micro and nanotechnology, energy production and in space, aircraft, automobile or domestic industry. In other words it would be very difficult (or impossible) to find area in which there is not bionic influence on development. The bionic influence on our life is much more wider then we can imagine. For many years the Man was fascinated by his technical achievements. Now, thanks to bionic the man can better understand the optimal solution worked out by the Nature in evolution process. This fact taught us a respect for natural surroundings and to understand that we are the part of it. The bionic integrate the scientists from different areas (mechanical, electrical or informatics engineering, chemists, physic, biologists, physician even economists) and gives new reasons for natural environment protection. From literature results that in the natural surroundings exists: $\sim 55000$ species of mammals, $\sim 31000$ of fishes, 10000 of birds, 8 800-of reptiles, and $\sim 1000000$ of insects and $\sim 300000$ of plants $[1,2]$. Each 
of this animals or plants created in evolution process original solutions which can be used as a pattern of mechanical structure and shape or surface structure design. From analysis of 218 papers results that in 28 papers the source of inspiration were mammals, in 20 fishes, in 11 birds, in 9 reptiles and in 46 insects. The number of papers as function of distributions: problems (Material, Movement, Function \& Behavior, Sensor) and stages of development (Idea, Research, Prototype, Product) is presented in "Figure 1". During last ten years number of articles and patents significantly increased. The special Journals which publish only papers connected with "bionic research" have been organized. So, it is right to state that now during each year a few hundreds of paper and a few tens of patents are published.

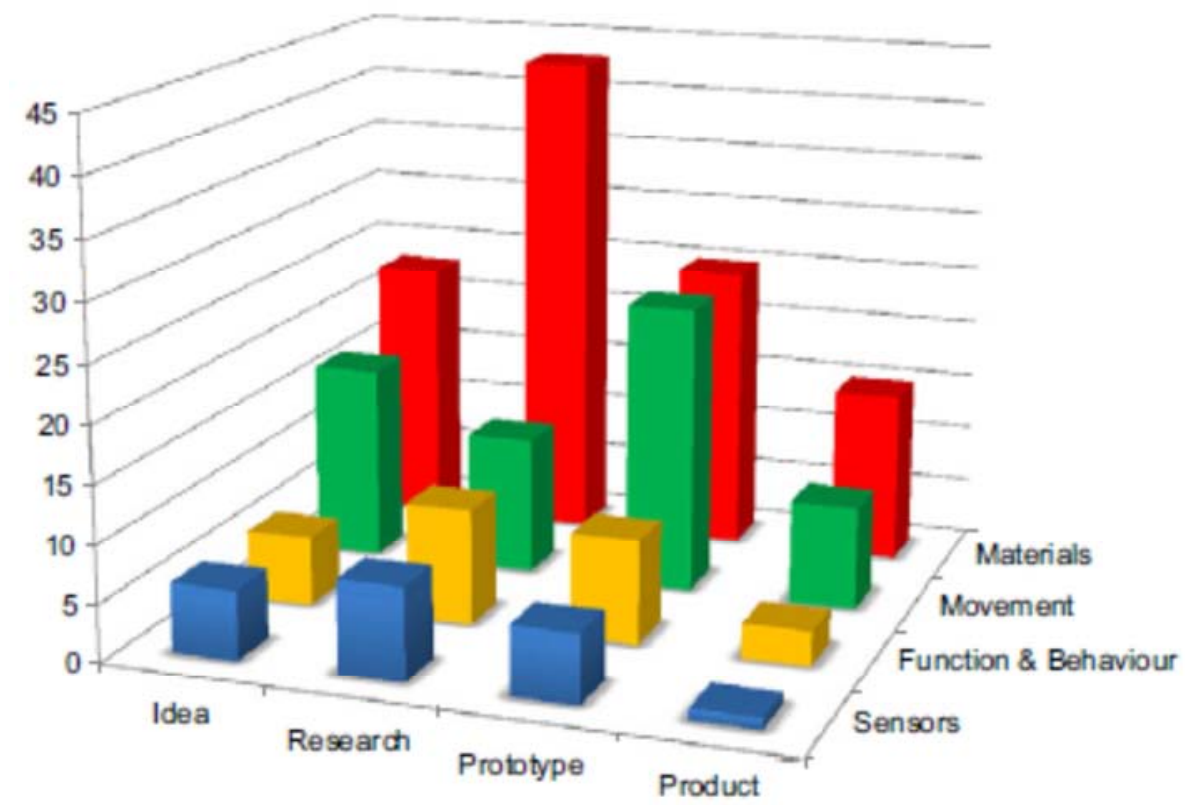

Figure 1. Distribution of problems (Material, Movement, Function \& Behavior, Sensor) and stages of development (Idea, Research, Prototype, Product) [2].

\section{Methodology of Bio-inspired Design}

Scientists evaluate that now people are able to take advantage of about $\sim 10 \%$ bionic solutions [1-4]. It results from the fact that sometimes it is very difficult to investigate objects, materials or processes occurring in natural surroundings. The another reason can be engineers limited knowledge about "bionic achievements". The bionic design is usually carried out by interdisciplinary teams (biologists, engineers, informatics, physics, chemists) in the following stages [1-19]:

1. Technical problem formulation.

2. Analysis of biological systems in order to find out bio-inspirations for technical problem solution.

3. Mathematical modeling of bionic systems (inside structure, surface layer structure, shape or process).

4. Bionic prototype of system or processes design and prepare test-stand for experiments.

5. Experimental investigations of bionic prototype (stiffness, stresses, distortions, mass, fatigue resistance, wear resistance, forces, friction, vibrations resistivity, process energy consumption, process efficiency, tool wear).

6. Evaluation of bionic prototype design or a new process advantages in order to make up decision about its further development.

\section{Bionic in Manufacturing Systems}

In manufacturing systems such areas of development can be taken into account: machine - tools and special technological equipment design and manufacturing, improvement of existed and looking for a new manufacturing processes. Development of machine - tools has two directions: improvement of mechanical parts properties including friction and wear of cooperated parts (machine-tool body) and improvement of organization of manufacturing process (control system, measurement system). Improvements in existing processes are connected with improvement of machine - tool and its control system. In order to express some ideas below examples of machine-tools mechanical parts bio-design, improvements and some problems of tool design will be presented. It is also necessary to stated that in THE NATURE all manufacturing processes of animals and plants are carrying out in additive way. So, very important for development of additive processes applied in research laboratories and industry is looking for bio-inspirations in processes occurring in the NATURE. Maybe it is the most important directions of their development.

\section{Mechanical Parts Structure Design}

From primary analysis results that significant improvement in quality of mechanical units of any machine systems, can be 
reached by introduction some bio-inspirations. Bio-inspirations make it possible to increase significantly load bearing efficiency, stiffness, vibrations resistance and decrease mass and distortion. Below the examples of such bio-inspirations are presented [4-7]:

1. Skeletons of mammals and birds have in relation to properties (stiffness, load bearing) very small weight "Figure 2". It is thanks to special inside macro and microstructure of bones; for example pigeon skeleton is only about $8-9 \%$ of its total mass [4],

2. Woodpeckers skull and beak thanks to a special inside microstructure have properties of vibration suppression-vibrations are absorb, dissipate and keep away of brain [7],

3. Bamboo stems are slim but stiff and with high toughness thanks to advanced inside micro, mezzo and macrostructure (Figure 4). Similarly the branch system of tree (Figure 3), leafs vein of giant water lily leaf (Figure 5) can inspire inside structures of machine-tools or other mechanical parts presented in Figures $6,7,8$ [5-7].
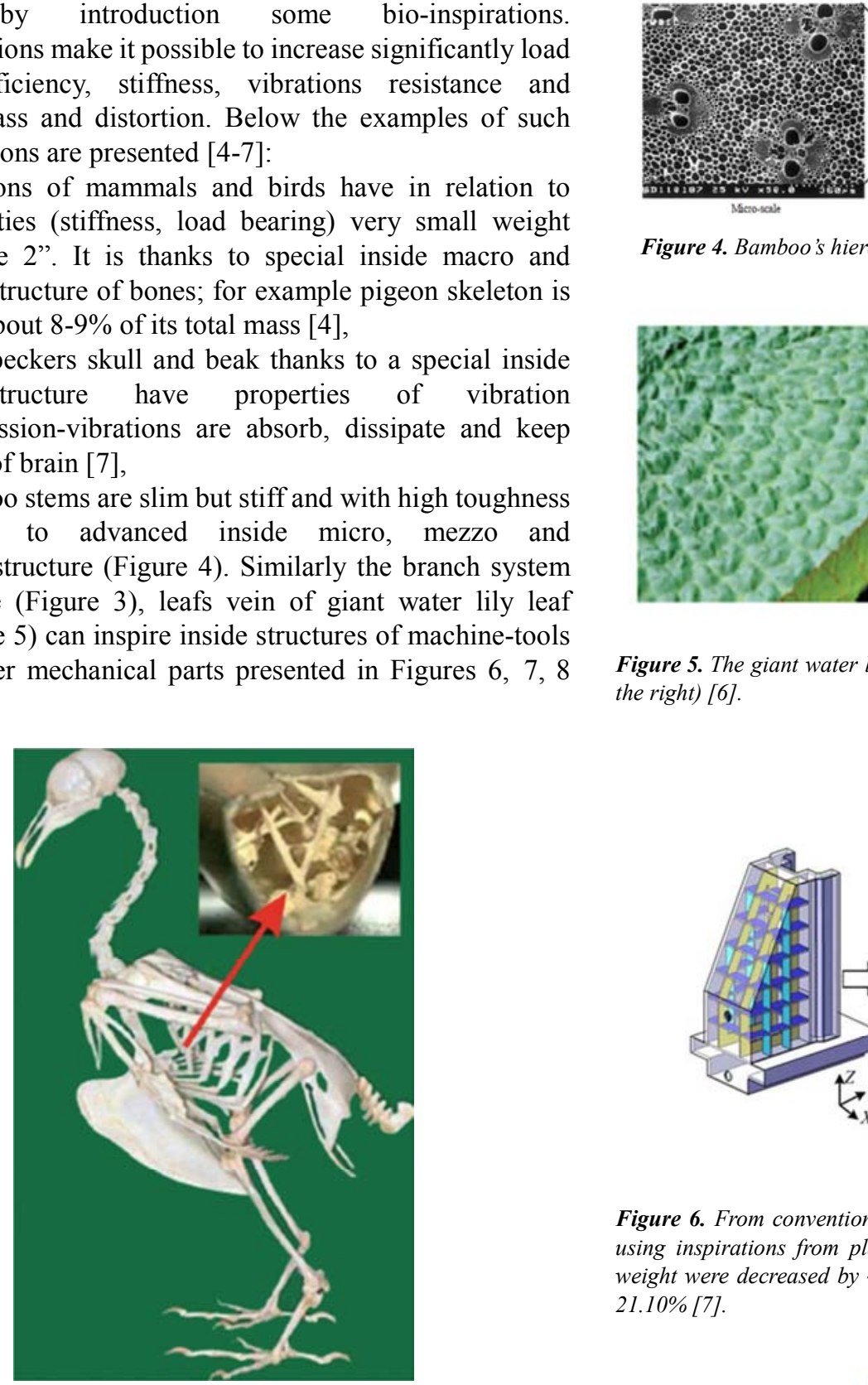

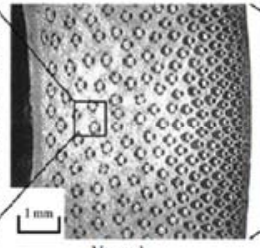

Vhosate

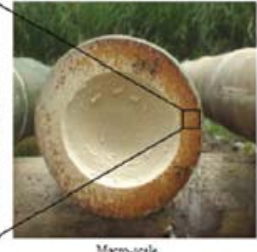

Urom

Figure 4. Bamboo's hierarchical inside structure in different scales [5].

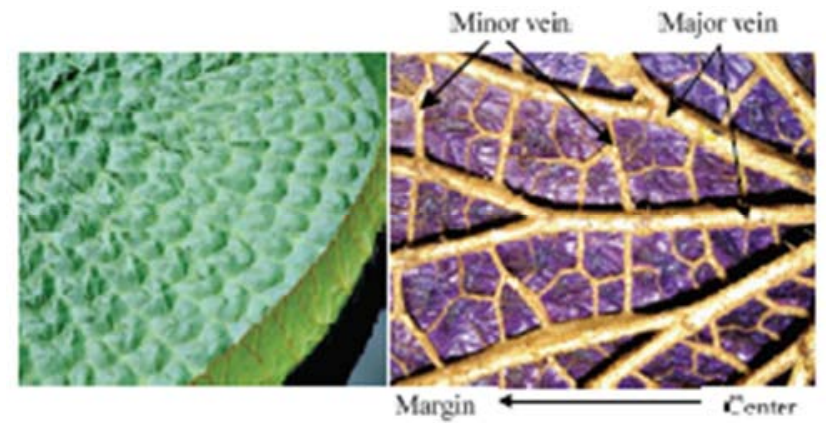

Figure 5. The giant water lily leaf (on the left) and its veins distribution (on the right) [6].

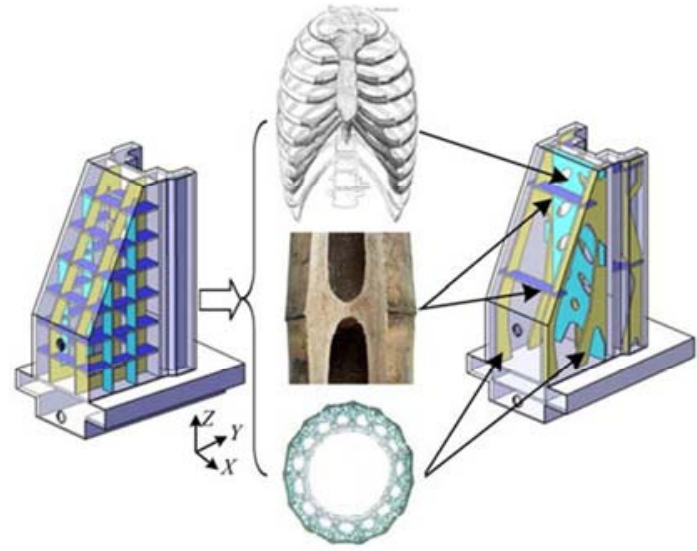

Figure 6. From conventional (on the left) to bionic (on the right) structure using inspirations from plants and birds. In bionic design distortion and weight were decreased by $\sim 45.90 \%$ and $6.13 \%$ while stiffness increased by $21.10 \%[7]$.

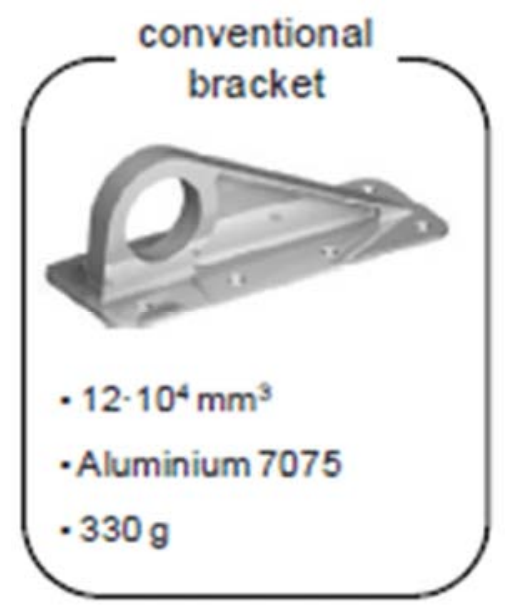

Figure 7. Conventional bracket [14].

Figure 3. Optimal structure of ordinary tree branch system [23]. 


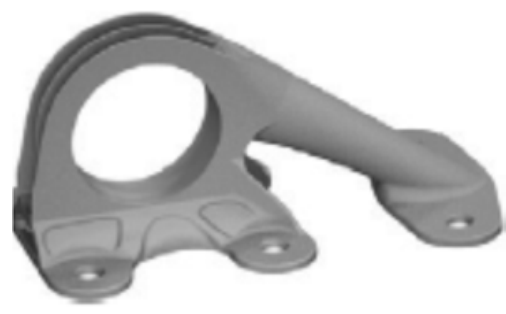

Figure 8. Bioinspired bracket [14].

Taking into account above presented methodology and some biological inspirations (structure of treetop systems, leaves of trees or flowers (Nenuphar), bamboo stems, bulrush or Mexican Cacti, beak of woodpeckers (which have properties of vibration suppression) [2-5] it was possible to work out bionic design of machine-tools units in which were achieved [3-6]: toughness increase of $53-124 \%$, stiffness increase of $21-43 \%$, weight decrease of $3-43 \%$, distortion decrease of $16-44 \%$.

In each case the anti-vibration properties of bionic constructions have been also significantly improved. For example in "Figure 9" the results of frequency measurements of original (conventional) and bionic models are presented. For example conventional and bionic design of machine-tool body (Figure 6) and aircraft bracket (Figures 7 and 8) are presented. Bracket bionic design is significantly lighter from conventional design but because of complicated shape it must be manufactured using Laser Additive Manufacturing, what generats additional costs. However savings of material and operational expenses during aircraft lifecycle are significantly higher [14]. Bionic lightweight design gives possibility of important improvements in the next aircraft generation.

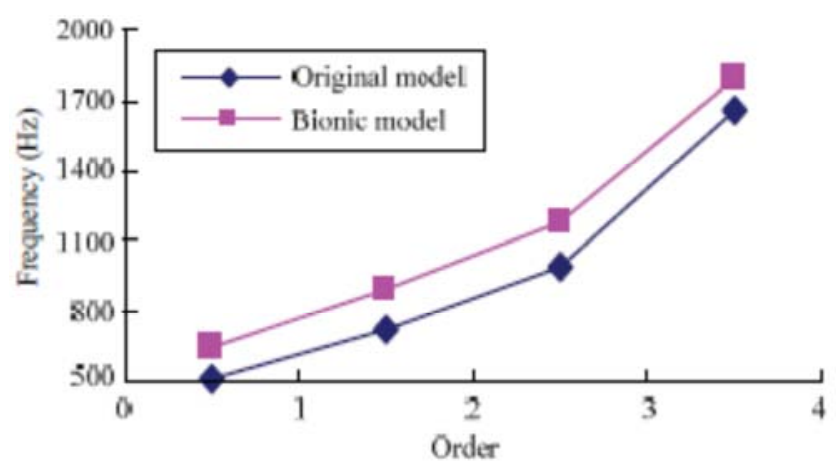

Figure 9. Results of dynamical tests: dynamic natural frequencies for original (conventional) and bionic model [6].

\section{Designing Surface Layer Properties}

Analysis of animal bodies proved that in the Nature there are not regular shapes. Similarly the analysis of surfaces occurring in natural surroundings proved that in the alive organisms there are not smooth surfaces. The smooth surfaces are not optimal from living conditions point of view. Bellow there are some examples. There are many animals which skin has a special geometrical structure with very low coefficient of friction. For example: sharks, snakes and dung beetles [2-4, 10-13]. The special butterfly wings structure was efficient bio-inspiration in designing surface structure of wind turbine blades $[10,11]$. Dung beetle has different surface structure on the body, wings and head (Figures 11, 12).

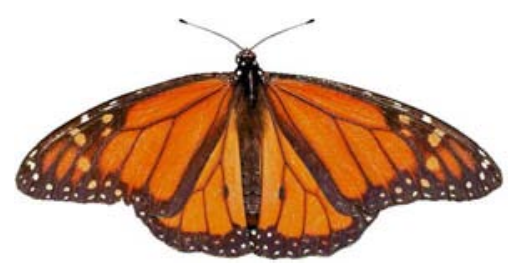

Figure 10. Butterfly Monarch (Danaus plexippus L.) as an inspiration for bionic wind turbine blades design [10, 11].

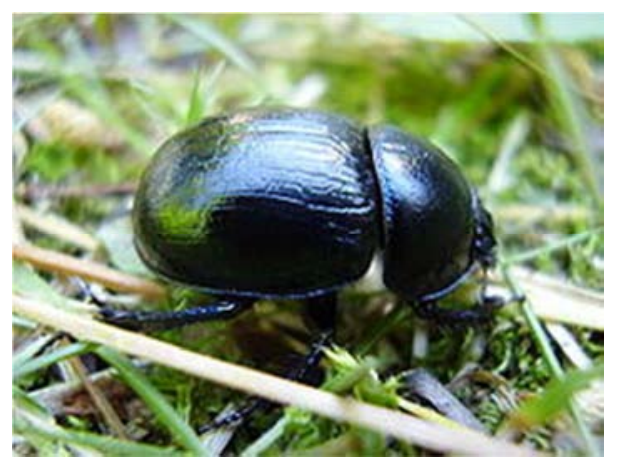

Figure 11. Dung beetle has the different structures of the head, body and wings [12].
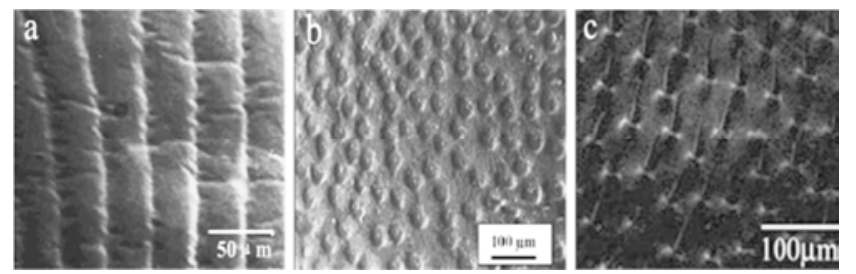

Figure 12. Different structures on wings $(a)$ and head $(b, c)$ of dung beetle (stripes, cavities and protrusions) [12, 16].

Structures presented in "Figure 12" were the inspirations for design surface layer structure for cooperated parts. All parts in experiments have been made of grey cast iron - GCI [12]. Parts with bionic surface layer structure have significantly higher (of $\sim 20$ to $53 \%$ ) fatigue wear resistance in comparison to samples with conventional smooth surface structure. Similar conclusion results from experiments carried out for samples made of steel [13].

\section{Bio-inspirations in Shape Design}

Analysis of shapes of animals body or its parts indicated that they are not regular. These shapes are optimal from its living conditions point of view. Usually this optimal shape gives very small coefficients of movement resistance and animals can move very fast with low energy consumption. The fore paw of mole rat and grasshopper jaw have been applied as models for agriculture tools $[8,9]$. Bionic solution make it possible to decrease the mean saw cutting force of about $28.17 \%$ and energy consumption of $\sim 12.85 \%$ (Figure 13 ). 

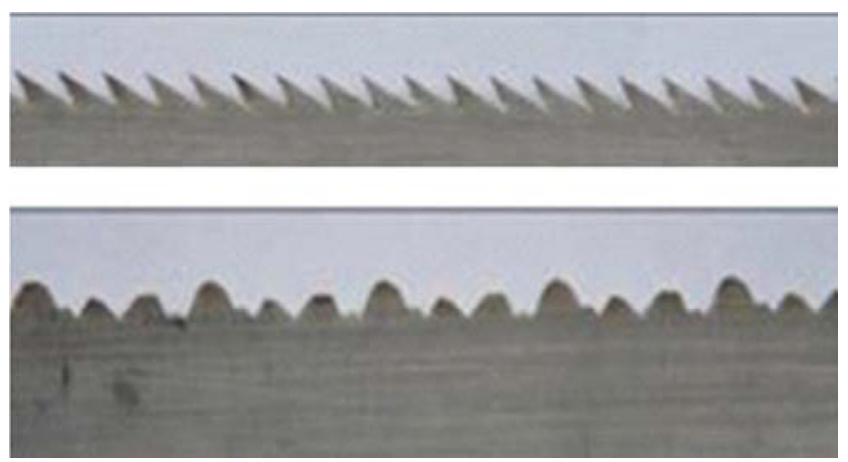

Figure 13. Cutting saw blade conventional (upper) and bionic one (lower) [9].

\section{New Bio-concept of Drilling}

In case of conditions with small gravitation (moon, asteroids) it is very difficult to create big axes force which is necessary to drill hole in conventional way with rotational movement and take sample of material. Because of this fact the research are carried out which aim is to work out methods of making holes on conditions that: equipment weight is smaller than $10 \mathrm{kG}$, depth of wholes $1-2 \mathrm{~m}$ and force about 0.5 $\mathrm{kG}$. The main bio-inspirations were taken from investigations of caterpillar peristaltic way of movement and method applied by wood wasp for building in wood channels and places for store eggs [16-18]. Wood wasp have ovipositor consisted with two parts sliding and move forward and backward (Figure 14) [17]. In "Figure 15" is presented way of doing holes based on Wood wasp ovipositor action.
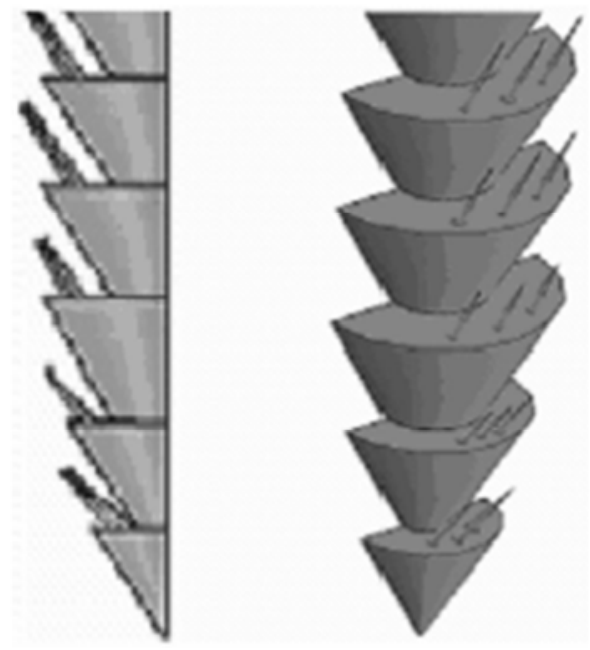

Figure 14. Scheme (2D) and (3D) of bioinspired by wood wasp tool for drilling holes.

Presented in Figure 16 equipment weight is less than $10 \mathrm{kG}$ and make it possible to reach about $1.5 \mathrm{~m}$ underneath an asteroid surface and take samples of material for investigations. For drilling holes in chalk (specific density: $1500 \mathrm{~kg} / \mathrm{m}^{3}$ ) using drill with diameter $18 \mathrm{~mm}$, together with increasing power from 2 to 11 [W], drilling speed increases from 4.0 up to $16 \mathrm{~mm} / \mathrm{min}$.

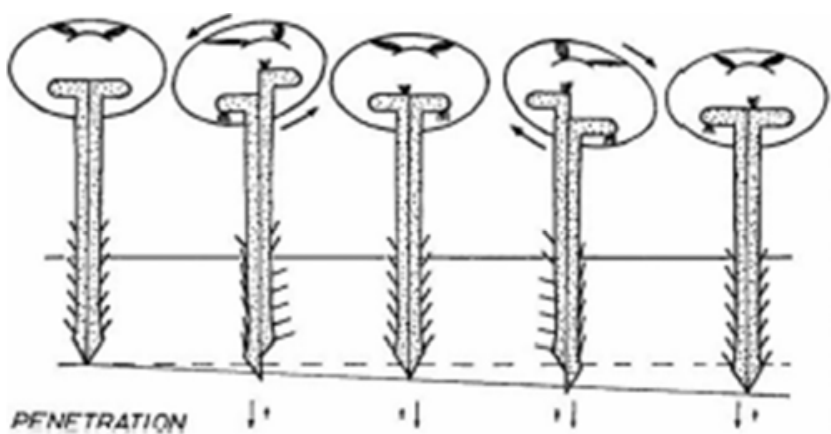

Figure 15. Wood wasp reciprocating drill - stage of penetration [17]
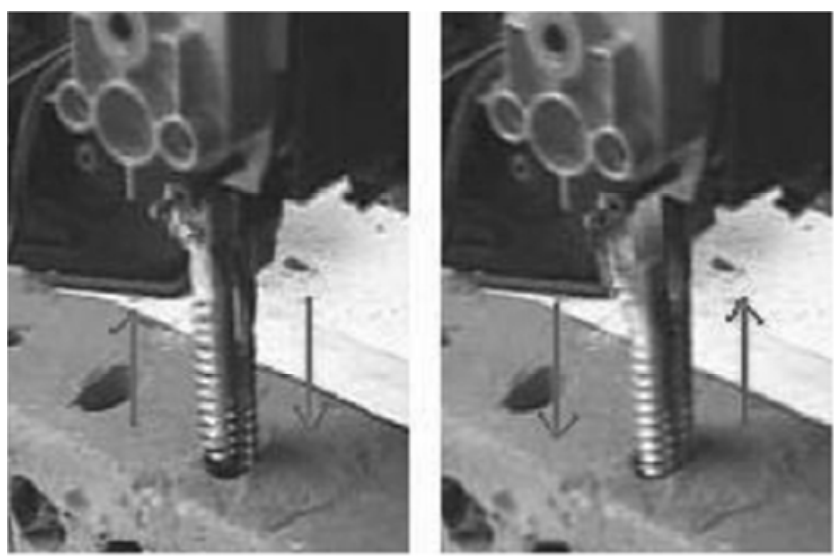

Figure 16. Lab-based test model for drilling when using tool from "Figure 14" and method presented in "Figure 15" [17].

\section{Bio-inspirations in Grinding Processes}

In the paper [15] have been presented new concepts for: self-sharpening tools, tools with better chip transport and higher abrasive wear resistance, a new nozzle concept for breaking air barriers and new strategies for adapting grinding to new environments. However further research and actual implementation of the presented ideas are needed. Nevertheless, this first study has revealed many interesting approaches: how bio-inspirations can bring more sustainability into grinding process. When analyzing grinding process from point of view biologically inspired improvements it was proposed [15]: 1. In order to improve grinding products transportation out of machining area and grinding wheel cleaning it is suggested to carry out process underwater with pressurized air injection to machining area; 2 . Taking into account self-cleaning property of lotus leaves the conception of grinding wheel with non-sticking pores was worked out; 3. The decreasing of grinding wheel wear is possible by applying nonsmooth surface as in Farrers Scallop shell and fiber - reinforced grinding wheel (as in bamboo inside structure); 4. The grinding wheel self sharpenning property can be improved by using multilayer grinding wheel inspired by multilayer teeth of "Kling Fish".

Bio-analysis of classical grinding process is a good starting point for improvement of classical, electrochemical and electrodischrge grinding processes. 


\section{Conclusions}

The bionic builds a bridge between "world of plants, animals and processes "developed by the Nature in evolution process and technical applications".
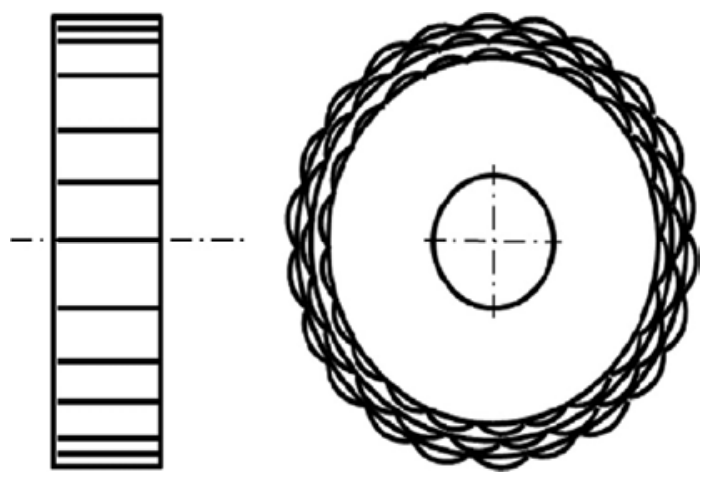

Figure 17. Inspired by shape of Farres Scalop Shell and Cling Fish teeth multilayer grinding wheel [15].

Using bionic solutions it is possible to solve satisfactory technical problems occurred in area of production engineering. Taking into account above presented methodology and some biological inspirations it was possible to work out bionic design of machine-tools units or tooling, which have significantly higher load bearing efficiency of $\sim 53-124 \%$, increase of stiffness of $\sim 21-43 \%$, weight decrease of $\sim 3-43 \%$, distortion decrease of $\sim 16-44 \%$. In each case where dynamic experiments were carried out the anti-vibration properties of bionic units or parts were also improved thanks woodpecker beak structure inspirations. Special shape of tools for agriculture for cutting soil, wheat or grass have been designed taking as biological inspirations shape of mole rat paw and grasshopper jaw. Bionic solution make it possible in case of saw to decrease the mean cutting force of $\sim 28.17 \%$ and energy consumption of $\sim 12.85 \%$. Surface geometrical structure of butterfly wings was an inspiration for bionic wind turbine blades design. Experimental research proved that "bionic turbine" has of $\sim 15 \%$ higher efficiency in comparison with turbine with smooth blades. It means that bionic blade take of $\sim 15 \%$ energy more from the wind. It could be assumed that when somebody put this turbine in movement in any fluid it transfer to the air or water or electrolyte significantly more energy in comparison to smooth turbine blades. Advantage of this statement can be taken in case of Wire Electrochemical Cutting (WECM) process. In classical macro WECM process the wire diameter is about $200 \mu \mathrm{m}$ [21]. So, it is possible to use wire with bionic structure (for instance as in butterfly wings or as in body of dung beetle). Its influence on electrolyte flow will be significantly more intensive in comparison to smooth wire. The same the anode surface depassivation and efficiency of dissolution products, hydrogen and heat transportation out of interelectrode area could be significantly improved and the speed of ECM cutting can be increased. In case of micro WECM it could be difficult because of smaller wire diameter of $\sim 10 \mu \mathrm{m}$ [20]. It looks as very interesting area of a new research.

Dung beetle has the different structures of the head, body and wings. Taking into account these structures the bionic surface structure of moving and cooperated parts have been designed. Experimental research proved that all samples made of grey cast iron-GCI with bionic structure have significantly higher (of $\sim 20$ to $53 \%$ ) fatigue wear resistance in comparison to samples with conventional smooth surface structure. Similar conclusion results from experiments for samples made of steel. In some cases improvement of details properties is possible only when complicated bionic structures are applied. In this case the problem of manufacturing arise. Here the advanced forming, joining, additive and removal processes should be applied. The special attention should be taken for additive manufacturing processes [22]. This fact of course increase costs of production but usually gains from object quality, its life time increase and material consumption decrease are significantly higher.

Literature analysis indicate that NOW in the area of conventional and unconventional manufacturing systems and processes the applications of bio-inspirations taken from plants or animals are very, very limited. Here bio-inspirations can be implemented satisfactory for:

1. Improving mechanical properties of machine - tools, tooling and tools;

2. Improving tribological properties of cooperated surfaces (machine tools, tooling);

3. Improving already applied processes or invent new manufacturing methods; for instance holes drilling without tool rotations and with very low forces (Figures 14-16).

Taking into account the results of improvements in classical grinding process reached by taking into account bio-inspirations it would be useful to start with research aiming to introduce bio-inspirations for unconventional manufacturing processes; including at first ECM and EDM grinding and other hybrid processes.

Special attention should be paid for additive manufacturing processes development because The Nature creates all alive organisms (plants and animal) in very advanced additive technologies $[3,4,22]$.

\section{References}

[1] Lothar W. Isenmann R., Moehrle M. G. Bionic in patents semantic - based analysis for exploitation of bionic principles in patents. Procedia Engineering 2011; 620-632-9.

[2] Luriie Luke E., Product and technology innovation: What can biomimicry inspire. Biotechnology Advances 2014; 1494-1505-32.

[3] Shu L. H., Ueda K., Chiu I., Cheong H. Biologically inspired design. CIRP - Annals - Manufacturing Technology 2011 673-693-60.

[4] Ruszaj A. Bionic impact on industrial production development. Advancess in Manufacturing Science and Technology $2015 \mathrm{Vol}$ 39 No 4 p. 5-22.

[5] Zhao L., Ma J., Wang T., Xing D., Lighweight designe of mechanical structures based on structural bionic methodology 2010 p. 224-231-Suppl. 7. 
[6] Zhao L., Ma J., Chen W., Guo H. Lightweight design and veryfication of gantry machining center crossbeam based on structural bionic. Journal of Bionic Engineering 2011 p. 201-206-8.

[7] Zhao L., Chen W., Ma J., Yang Y. Structural bionic design and experimental veryfication of a machine tool column. Journal of Bionic Engineering 2008 p. 46-52-Suppl.

[8] Li M., Chen D., Zhang S., Tong J. Biommimetic design of a stubble cutting disc using finite element analysis. Journal of Bionic Engineering 2013 p. 118-127-10.

[9] Jia H., Li Ch., Zhang Z., Wang G., Design of bionic saw blade for corn stalk cutting. Journal of Bionic Engineering. 2013 p. 497-505-10.

[10] Kovalev I. The functional role of hollow region of the butterfly *Pyrameis atlanta (L) scale. Journal of Bionic Engineering 2008 p. $224-230-5$

[11] Kovalev I. From butterfly to wind turbine. Wind Engineering 2010, Vol. 34 No 4 p. 351-360.

[12] Chen Z., Lu S., Song X., Zhang H., Yang W., Zhou H. Effect of bionic units on the fatigue wear of gray iron surface with different shapes and distributions. Optics \&Laser Technology 2015 p. 166-174-66.

[13] Lu J., Yang Ch., Zhang L., Feng A., Jang Y. Mechanical properties and microstructure of bionic non-smooth stainless steel surface by laser multiple processing. Journal of Bionic Engineering 2009 p. 180-185-6.

[14] Emmelmann C., Sande P., Kranz J., Wycisk E. Laser additive manufacturing and bionics: Redefining lightweight design. Physics Procedia. 2011p. 364-368-12.

[15] Linke B. S., Moreno J. New concept for bio-inspired grinding. Journal of Manufacturing Processes 2015 p. 73-80-19.

[16] Gau K., Sun Y-H., Ren LQ., Cao P-L., Li W-T., Fan H-K. Design and analysis of temary coupling bionic bits. Journal of Bionic Engineering 2008 p. 53-59-Suppl.

[17] Gao Y., Ellery A., Jaddou M., Vincent J., Ecklersley S. Planetary micro-penetrator concept study with biomimetic drill and sampler design. IEEE Transactions on Aerospace and Electronic Systems 2007 Vol. 43 No 3 p. 875-885.

[18] Nakamura T., Kato To., IwanagaT., MuranakaY. Development of peristaltic crawling robot based on eartworm locomotion. Journal of Robotics and Mechatronics 2006 Vol. 18 No 3 p. 299-300.

[19] Li G., Li W., Zhang J., Zhang H. Analysis and design of asymetric oscilation for caterpilar - like locomotion. Journal of Bionic Engineering 2015 p. 190-203-12.

[20] Xu K., Zeng Y., Li P., Zhu D., Study of surface roughness in wire electrochemical micromachining. Journal of Materials Processing Technology 2015 p. 103-109-222.

[21] Zeng Y., Yu Q., Fang X., Xu K., Li H., Qu H. Wire electrochemical machining with monodirectional travelling wire. International Journal of Adv Manuf Technol-published online 07. 01. 2015.
[22] www.nanoscribe.de.

[23] Oczoś K. E., Kawalec A., Kształtowanie metali lekkich, Wydawnictwa Naukowe PWN 2012.

[24] G. Eason, B. Noble, and I. N. Sneddon, "On certain integrals of Lipschitz-Hankel type involving products of Bessel functions," Phil. Trans. Roy. Soc. London, vol. A247, pp. 529-551, April 1955. (references).

[25] J. Clerk Maxwell, A Treatise on Electricity and Magnetism, 3rd ed., vol. 2. Oxford: Clarendon, 1892, pp. 68-73.

[26] I. S. Jacobs and C. P. Bean, "Fine particles, thin films and exchange anisotropy," in Magnetism, vol. III, G. T. Rado and H. Suhl, Eds. New York: Academic, 1963, pp. 271-350.

[27] K. Elissa, "Title of paper if known," unpublished.

[28] R. Nicole, "Title of paper with only first word capitalized," J. Name Stand. Abbrev., in press.

[29] Y. Yorozu, M. Hirano, K. Oka, and Y. Tagawa, "Electron spectroscopy studies on magneto-optical media and plastic substrate interface," IEEE Transl. J. Magn. Japan, vol. 2, pp. 740-741, August 1987 [Digests 9th Annual Conf. Magnetics Japan, p. 301, 1982].

[30] M. Young, The Technical Writer's Handbook. Mill Valley, CA: University Science, 198.

[31] Krejcie, R. V. and D. W. Morgan (1970) Determining Sample Sizes for Research Activities. Educational and Psychological Measurement 30, 607-610.

[32] Kass, R. E. and A. E. Raftery (1995). Bayes Factors. Journal of the American Statistical Association 90, 773-794.

[33] Spiegelhalter, D. J., N. G. Best, B. P. Carlin, and A. van der Linde (2002). Bayesian Measures of Model Complexity and Fit (with discussion). Journal of the Royal Statistical Society: Series B 64, 583-639.

[34] Ebenebe, C. I., Anigbogu, C. C., Anizoba, M. A. and Ufele, A. N. (2013). Effect of various levels of Moringa Leaf Meal on the Egg Quality of Isa Brown Breed of Layers. Advances in Life Sciences and Technology 14: 45-49.

[35] Fahey, J. W., Zakmann, A. T., and Talalay, P. (2001). The chemical diversity and distribution of glucosinolates and Isothiocyanates among plants. Corrigendum Phytochemistry, 59: 200-237.

[36] Greg, M. E. (2008). Effect of enzymes on cellulose, European Journal of Applied Microbiology Biotechnology, 40: 167-171.

[37] Onunkwo, D. N and George, O. S (2015). Effects of Moringaoleifera leaf meal on the growth performance and carcass characteristics of broiler birds. IOSR Journal of Agriculture and Veterinary Science, 8 (3II): 63-66.

[38] El Tazi, S. M. A. (2014). Effect of feeding different levels of Moringaoleifera leaf meal on the performance and carcass quality of broiler chicks. International Journal of Science and Research, 3 (5): 147-151. 